\title{
Problematic of Vascular Access for Hemodialysis in Sub-Saherienne Africa: Experience of Dakar \\ Kane $\mathrm{Y}^{1^{*}}$, Cisse $\mathrm{MM}^{2}$, Gaye $\mathrm{M}^{3}$, Seck $\mathrm{SM}^{4}$, Lemrabott $\mathrm{AT}^{2}$, Ba ${ }^{3}$, Faye $\mathrm{Maria}^{2}, \mathrm{Ka} \mathrm{EF}^{2}$, Niang $\mathrm{A}^{2}$ and Diouf $\mathrm{B}^{2}$
}

${ }^{1}$ Department of Nephrology and Internal medicine of Assane Seck University/Ziguinchor, Senegal

${ }^{2}$ Department of Nephrology, Teaching Hospital Aristide Le Dantec /Dakar, Senegal

${ }^{3}$ Department of Cardiovascular and Thoracic Surgery of Teaching hospital Fann/Dakar, Senegal

${ }^{4}$ Department of Nephrology, Gaston Berger University/Saint Louis, Senegal

\begin{abstract}
Aim: Vascular access is important for a good survive in hemodialysis. It can be temporary or permanent, and needs particular attention because of possible complications, especially infectious. We conducted a study to determine the type and the outcome of vascular access in two hemodialysis units in Dakar.

Materials and Methods: A multicenter retrospective study was conducted from the $1^{\text {st }}$ January 2005 to 10 September 2010 in two hemodialysis centers: Hospital Aristide Le Dantec and the MDTC (Multifunctional Diagnosis and Treatment Center) of Dakar. All the patients- regularly dialyzed since at least three months in these centers were included.

Results: Sixty five patients were included. The mean age was 50.2 years with a sex ratio of 1.7 . The mean duration in hemodialysis was 23.2 month. Only five patients $(7.80 \%)$ had an AVF before starting in hemodialysis. Sixty patients $(92.2 \%)$ started dialysis with a central venous catheter. Among them, $49(81.6 \%)$ had a double lumen femoral catheter and 11 had a jugular one with 4 tunneled. Complications of vascular access were noted for 23 patients (39.7\%) with 12 infections. Blood culture was positive for Staphylococcus Aureus in seven cases. Seven patients presented lower limb thrombophlebitis. Thrombosis of the catheter was noted in four patients. Radial arterio-venous fistula (AVF) was the first intention permanent access in 41 cases (64.1\%) followed by cephalic AVF in 14 cases (21.9\%) and basilic AVF in $9(14 \%)$. AVF complications were presented in $56.9 \%$ of case (40 patients). Most of them was early defect in 18 cases $(27.7 \%)$, thrombosis in $9(13.8 \%)$ and stenosis in $5(7.7 \%)$. Radial AVF infection to Staphylococcus Aureus was noted in 3 cases, and one pseudo aneurysm was noted.
\end{abstract}

Conclusion: Vascular access for hemodialysis is a great problem in Senegal. More than two third of our patients start dialysis on venous catheters, this is far from the clinical practice guidelines.

Keywords: Vascular access; Hemodialysis; Central venous catheter; Arterio-venous fistula

\section{Introduction}

A good vascular access is a necessary condition for an adequate hemodialysis session. In Senegal, according to a survey carried out in 2003, there are 87 new cases of chronic renal failure (CRF) every year [1]. Furthermore most of the patients are referred in nephrology for the first time in end- stage renal disease (ESRD) requiring dialysis in emergency [2]. Hemodialysis efficiency depends mainly on quality of vascular access. In Senegal a few data are available on hemodialysis VA. We performed a study in order to determine the nature and outcomes of vascular access in two hemodialysis units based in Dakar.

\section{Patients and Methods}

This is a retrospective and multi-center study from January $1^{\text {st }} 2005$ to September $10^{\text {th }} 2010$ in the hemodialysis units of Aristide Le Dantec hospital and the MDTC (Multifunctional Diagnosis and Treatment Center). All ESRD patients who were regularly hemodialysed since at least three months were included. Data were collected from medical records in each center the patients whose medical files were not complete and those who were not taken care of on a regularly basis, were not considered by the trial. For every patient concerned, the parameters below were collected:

- The epidemiological data: age, sex, causal nephropathy, length in hemodialysis;

- The type of vascular access at the inception of the hemodialysis session;
- About central venous catheters: site, catheter type, length of use, complications, their treatment and evolutions;

- About arterio-venous fistula (AVF): date of preparation, AVF type, survival time, complications, their treatment and evolutions;

Transitory vascular accesses were represented by central venous catheters; and permanent vascular accesses by arterio-venous fistulas. Early failure was determined by inoperative catheter before first puncture is performed. Data have been captured and analyzed using EPI info, version 3.3.2. In the descriptive section, the calculation of frequencies has been carried out for qualitative variables. Concerning quantitative variables, the calculation of averages have been done. During the analytical section, statistical test have been used: the Chisquare or the Fisher tests to compare the rates as per conditions of application, and the Student test for median comparison. The bivariate analysis between the complications frequency of transitory vascular accesses and some parameters, especially the age average, sex, initial

*Corresponding author: Yaya Kane, Department of Nephrology and Internal medicine of Assane Seck University/Ziguinchor, Senegal, Tel: 002217750021 65; E-mail: yayuskanus@yahoo.fr

Received: September 09, 2015; Accepted: September 23, 2015; Published: September 30, 2015

Citation: Kane Y, Cisse MM, Gaye M, Seck SM, LemrabottAT, et al. (2015) Problematic of Vascular Access for Hemodialysis in Sub-Saherienne Africa: Experience of Dakar. J Nephrol Ther 5: 216. doi:10.4172/2161-0959.1000216

Copyright: @ 2015 Kane Y, et al. This is an open-access article distributed under the terms of the Creative Commons Attribution License, which permits unrestricted use, distribution, and reproduction in any medium, provided the original author and source are credited. 
nephropathy, access time of use, femoral site and the first dialysis access has been done. The trials are statistically significant when the $P$ value is less than $0.05(\mathrm{p}<0.05)$.

\section{Results}

Data regarding 248 patients have been pooled, 65 of which have been included in the study. The average age was 50.2 (limits: 15 and 75 years). There were 30 men and 35 women, i.e. a sex ratio (man/ woman) of 0.85 . Nephroangiosclerosis was the first initial nephropathy observed among 25 patients (38.5\%), followed by chronic primitive glomerulonephritis and diabetic nephropathy, in respectively 11 (16.9\%) and $10(15.4 \%)$ cases. In 8 cases (12.3\%), the cause could not be determined. The other etiologies were tubulointerstititial nephropathy, autosomal dominant renal polycystosis and the lupus, respectively 5 , 4 and 2 cases. The average length in hemodialysis was 23.2 months (limits: 3 and 34 months).

The first hemodialysis (HD) session was done using central venous catheter with 60 patients (92.2\%). Among 49 patients (81.9\%), doublelumen femoral catheter was applied, and with 11 patients $(18.4 \%)$, double-lumen jugular was used, $4(6.6 \%)$ of them received tunneled dialysis. The median duration of catheters was 4.9 months. 23 patients showed catheter-related complications, among which 12 (52\%) were infectious and $11(48 \%)$ of thrombosis-type. All infections were located at the femoral site. Hemocultures were positive in 7 patients (Staphylococcus aureus isolates). Among the 12 patients suffering from catheter-related infection, 11 patients had a favorable evolution after undergoing anti-biotherapy and catheter ablation. Lower limb thrombophlebitis was observed in 7 patients. 4 patients showed a catheter-related thrombosis, which resulted in an ablation in $4.7 \%$ cases. Catheter ablation was applied in all patients who suffered from venous or catheter-related thrombosis. 4 deaths, $6.2 \%$, during evolution, 3 of them were directly associated with vascular access of the central venous catheter type ( 1 case of serious sepsis, 1 pulmonary embolism, 1 catheter-related bleeding).

Only 5 (7.8\%) patients received an AVF before starting HD treatment. Radial AVF was the first permanent vascular access envisaged in 41 cases, i.e. $64.1 \%$; cephalic AVF followed with 14 cases, i.e. $21.9 \%$, and then basilic AVF in 9 cases, $14 \%$. In our survey, the average AVF survival was $17.17 \pm 17$ months (limits: 1 and 29 months). 40 patients (56.9\%) had AVF-related complication. They were early failures in 18 cases $(27.7 \%)$, afterwards $9(13.8 \%)$ patients got thrombosis, and 5 patients $(7.7 \%)$ got stenosis. Three (3) patients (4.6\%) had radial AVF staphylococcus aureus infections. One patient showed a false aneurysm. The treatment consisted mainly of applying a new AVF in 35 cases (55.4\%). Among the 9 patients suffering from AVF-related thrombosis, 3 got a successful fibrinolytic treatment and for the others, AVF resumption. Dealing with AVF infections requires the cancellation of hemodialysis, the application of anti-biotherapy and cares done locally with favorable evolution.

About transitory vascular access, a statistically significant link was observed between the occurrences of complications and the average age of 44 , the femoral site and the life span of over 6.4 months. The occurrences of complications were not associated with initial nephropathy and the sex (Table 1).

As for permanent vascular access, there was a statistically significant link between occurrences of complications and the average age of 54.6, and radial AVF. There was no statistically significant link between occurrences of complications and sex, initial nephropathy and life span (Table 2).

\begin{tabular}{|c|c|c|c|c|c|}
\hline & & \multicolumn{2}{|c|}{$\begin{array}{c}\text { Complications of Transitory } \\
\text { Vascular Access }\end{array}$} & \multirow{2}{*}{$\mathbf{P}$} & \multirow{2}{*}{ OR } \\
\hline & & Yes & No & & \\
\hline $\begin{array}{c}\text { Mean age } \\
\text { (years) }\end{array}$ & & 44.7 & 53.3 & $0.02^{* *}$ & - \\
\hline \multirow{2}{*}{ Sex } & Male & $10(33.3 \%)$ & $20(66.7 \%)$ & 0.10 & \\
\hline & Female & $13(37.1 \%)$ & $22(62.9 \%)$ & & \\
\hline \multirow{7}{*}{ Nephropathy } & NAS & $8(32 \%)$ & $17(68 \%)$ & & \\
\hline & $\mathrm{GN}$ & $4(36.4 \%)$ & $7(63.6 \%)$ & & \\
\hline & UN & $4(50 \%)$ & $4(50 \%)$ & 0,17 & - \\
\hline & DN & $2(20 \%)$ & $8(80 \%)$ & & \\
\hline & CTIN & $3(60 \%)$ & $2(40 \%)$ & & \\
\hline & PKR & $0(0 \%)$ & $4(100 \%)$ & & \\
\hline & LN & $2(100 \%)$ & $0(0 \%)$ & & \\
\hline $\begin{array}{l}\text { Duration } \\
\text { (Months) }\end{array}$ & & 6.4 & 3.9 & $0.004^{* *}$ & - \\
\hline \multirow{2}{*}{$\begin{array}{l}\text { First dialysis } \\
\text { access }\end{array}$} & Catheter & $23(39.7 \%)$ & $35(60.3 \%)$ & $0.038^{* *}$ & Undefined \\
\hline & AVF & 0 & $7(100 \%)$ & & \\
\hline \multirow{2}{*}{ Femoral site } & Yes & $22(46.8 \%)$ & $25(53.2 \%)$ & $0.0003^{* *}$ & Undefined \\
\hline & No & $0(0 \%)$ & $18(100 \%)$ & & \\
\hline
\end{tabular}

NAS: Nephroangiosclerosis; GN: Glomerulonephritis; UN: Unknown Nephropathy DN: Diabetic Nephropathy; CTIN: Chronic Tubulointerstitial Nephropathy; PKD: Polycystic Kidney Disease; LN: Lupus Nephritis

Table 1: Frequency of occurrence of complications of transitory vascular access for different patients.

\begin{tabular}{|c|c|c|c|c|}
\hline & & \multicolumn{2}{|c|}{$\begin{array}{l}\text { Complications of permanent } \\
\text { Vascular Access }\end{array}$} & \multirow[t]{2}{*}{$\mathbf{P}$} \\
\hline & & Yes & No & \\
\hline $\begin{array}{l}\text { Mean age } \\
\text { (years) }\end{array}$ & & 54.6 & 48.43 & 0.127 \\
\hline \multirow{2}{*}{ Sex } & Male & $7(23.3 \%)$ & $23(76.7 \%)$ & 0.93 \\
\hline & Female & $12(34.3 \%)$ & $23(65.7 \%)$ & \\
\hline \multirow{7}{*}{$\begin{array}{c}\text { Initial } \\
\text { Nephropathy }\end{array}$} & NAS & $6(24 \%)$ & $19(76 \%)$ & \\
\hline & GN & $5(45.5 \%)$ & $6(54.5 \%)$ & \\
\hline & UN & $2(25 \%)$ & $6(75 \%)$ & \\
\hline & DN & $3(30 \%)$ & $7(70 \%)$ & 0.18 \\
\hline & CTIN & $0(0 \%)$ & $5(100 \%)$ & \\
\hline & PKD & $1(25 \%)$ & $3(75 \%)$ & \\
\hline & LN & $2(100 \%)$ & $0(0 \%)$ & \\
\hline \multirow{4}{*}{ First AVF } & Radial & $12(29.3 \%)$ & $29(70.7 \%)$ & \\
\hline & Cephalic & $2(14.3)$ & $12(85.7 \%)$ & \\
\hline & $\begin{array}{l}\text { Superficialized } \\
\text { Basilica }\end{array}$ & $5(71.4 \%)$ & $2(28.6 \%)$ & $0.04^{* * *}$ \\
\hline & $\begin{array}{c}\text { Basilica } \\
\text { unsuperficialized }\end{array}$ & $0(0 \%)$ & $2(100 \%)$ & \\
\hline $\begin{array}{l}\text { Duration } \\
\text { (Months) }\end{array}$ & & 5.47 & 4.66 & 0.42 \\
\hline
\end{tabular}

NAS: Nephroangiosclerosis; GN: Glomerulonephritis; UN: Unknown Nephropathy; DN: Diabetic Nephropathy; CTIN: Chronic Tubulointerstitial Nephropathy; PKD: Polycystic Kidney Disease; LN: Lupus Nephritis

Table 2: Frequency of occurrence of complications of permanent vascular access for different patients.

\section{Discussion}

Only 7.8\% started hemodialysis session using AV fistula. Our findings were similar to those of Medkouri et al., who reported recourse 
to temporary access in $83.6 \%$ of the patients in Morocco [3]. We first used temporary central venous catheter, in over 10 to $20 \%$ cases of dialyzed patients, as recommended by good practice guidelines [4]. This is done because most of our patients have reached end stage CRF when they are admitted in nephrology for the first time; so dialysis is used as emergency treatment. In North America and Europe where over $80 \%$ of the patients are examined by a nephrologist at least one month before starting dialysis care, only 2 to $3 \%$ of the patients are involved in temporary access [5].

Femoral site was mostly used as first transitory vascular access in $72.3 \%$ of the patients, jugular site follows in 11 patients (16.9\%) whom 4 received tunneled dialysis. Our findings do not match the literary records which recommend internal jugular access first because of its anatomic characteristics and low morbidity [6-8]. In the US and in Canada, tunneled catheters are used in $64 \%$ of hemodialyzed patients; contrarily to Europe, $74 \%$ of dialyzed patients receive native AVF [9]. In our study, catheter tunneling is hardly applied since most patients cannot afford to pay for it. Infections were the most widely observed complications in our patients $(20 \%)$. Such prevalence is much higher than what is recorded in Europe and the US, respectively 2 to $3 \%$ [10-12]. This can be explained by the fact that central catheters are commonly used; they are kept for a long time (4.9 \pm 3 months). The length and femoral site of the catheter are linked with higher risk of infections, as reported in some surveys $[13,14]$. The prevalence of high infections in the femoral site can be justified by neighboring perineal area, and especially by maceration in tropical environment. The Staphylococcus aureus is generally reported as the root cause of bacteremia in hemodialyzed patients $[15,16]$. These serious infections cause very high morbidity/mortality. This has been isolated from the hemoculture which involved 7 patients in our study. The prevalence of the host vein thrombophlebitis was lower than the observed in Morocco (26.4\%) [17], and in Nigeria (11\%) [18]. This constitutes, on top of the other mechanical dysfunctions, the main cause of catheter ablation $[19,20]$, though undervalued in our study where the ultrasound diagnosis was just done relying on obvious clinical signs.

In our survey, radio-cephalic arterio-venous fistula has been the most used as first permanent vascular access, followed by brachiocephalic and brachiobasilic fistula.

Arterio-venous graft was not discussed in our study. We opted for radial AVF first, in most cases, in order to lower the risks of distal ischemia, high blood flow, and preserving the proximal portion of the limb vascular network for forthcoming AVF. These are the views of Bourquelot et al., who has used radial AVF as first vascular access in $74 \%$ of his patients. He was seeking to minimize the incidence of ischemic complications [21]. His choice is different from Jennings' [22] who gave priority to proximal brachiocephalic AFV just to be quickly functional without running the risk of falling early thrombosis. On average, an AVF lasted 17.17 months according to our study. Median survival for the first native AVF in our patients was shorter compared to the survey carried out by Ravani et al., where a 70-month survival rate [23] was reported. Such difference could be justified by the fact that our patients had undergone shorter dialysis exposure $(23.2 \pm 18$ months on average). Early failure was the most common complication (27.7\% of the cases) followed by thrombosis (13.8\%), stenosis $(7.7 \%)$, infections (4.6\%), and aneurysms (3\%). Our findings are different from those of Bensalem [24]. He observed $62 \%$ of thrombosis, $23 \%$ of infections and $15 \%$ of aneurysms. This difference could be justified by the high rate of diabetic patients among the people targeted by the study. We could explain the high rate of early failure because vascular network exploration was not done prior to AVF creation and the delay in setting this up. The basic treatment for AVF complications is surgery (55.4\%); consisting in making up a new AVF. This is due to the fact that interventional angioplasty and radiology are not available in our technical facilities.

\section{Conclusion}

Vascular access in hemodialysis is a real problem in Senegal. In fact, two thirds of our patients undergo their first dialysis by way of central venous catheter, especially femoral. This operation is far beyond the requirements in terms of good medical practices. Radial AVF, the first access envisaged, is associated with high risk of complications.

\section{References}

1. Diouf B, Ka EF, Niang A, Diouf ML, Mbengue M, et al. (2000) [Etiologies of chronic renal insufficiency in a adult internal medicine service in Dakar]. Dakar Med 46: 1-4.

2. Diouf B, Niang A, Ka EH, Badiane M, Diop TM (2003) Chronic renal failure in one Dakar Hospital department. Dakar Med 48: 185-188.

3. Medkouri G, Aghai R, Anabi A, Yazidi A, Benghanem MG, et al. (2006) Analysis of vascular access in hemodialysis patients : A report from a dialysis unit in Casablanca. Saudi J Kidney Dis Transplant 17: 516-520.

4. (2001) NKF-K/DOQI Clinical guidelines for vascular access: update 2000. Am J Kidney Dis 37: 137-181.

5. Leye A, Diouf B, Ndongo S, Niang A, Ka EF, et al. (2004) [Secondary hyperparathyroidism of chronic hemodialysis]. Dakar Med 49: 23-27. [Article in French]

6. Canaud B, Beraud JJ, Joyeux H, Mion C (1986) Internal jugular vein cannulation with two silicone rubber catheters: a new and safe temporary vascular access for hemodialysis. Thirty months' experience. Artif Organs 10 : 397-403.

7. Montagnac R, Bernard C, Guillaumie J, Hanhart P, Clavel P, et al. (1997) Indwelling silicone femoral catheters: experience of three haemodialysis centres. Nephrol Dial Transplant 12: 772-775.

8. Zaleski GX, Funaki B, Lorenz JM, Garofalo RS, Moscatel MA et al. (1999) Experience with tunneled femoral hemodialysis catheters. AJR Am J Roentgenol 172: 493-496.

9. Mendelssohn DC, Ethier J, Elder SJ, Saran R, Port FK, et al. (2006) Hemodialysis vascular access problems in Canada: results from the dialysis outcomes and practice Patterns Study (DOPPS II). Nephrol Dial Transplant 21: 721-728.

10. Allon M (2004) Dialysis catheter-related bacteremia: treatment and prophylaxis. Am J Kidney Dis 44: 779-791.

11. Jean $G$ (2001) [Incidence and risk factors for infections from hemodialysis catheters]. Nephrologie 22: 443-448. [Article in French]

12. Kolff WJ (2002) The artificial kidney and its effect on the development of other artificial organs. Nat Med 8: 1063-1065.

13. Goetz AM, Wagener MM, Miller JM, Muder RR (1998) Risk of infection due to central venous catheters: effect of site of placement and catheter type. Infect control Hosp Epidemiol 19: 842-845.

14. Manfred M, Gere SP, Wilfred D (1996) Malposition of a dialysis catheter in the accessory hemiazygos vein. Anesth Analg 83: 883-885.

15. Bevc S, Pecovnik-Balon B, Ekart R, Hojs R (2007) Non-insertion-related complications of central venous catherization-temporary vascular access for hemodialysis. Ren Fail 29: 91-95.

16. Montagnac R, Schillinger F, Eloy C (2003) Prévention des bactériémies liées aux cathéters veineux centraux en hémodialyse : intérêt d'un soin du site d'insertion par un mélange de rifampicine et de protamine. Nephrologie 24: 159-165.

17. Kroencke TJ, Taupitz M, Arnold R, Fritsche L, Hamm M (2001) Threedimensional gadolinium-enhanced magnetic resonance venography in suspected thrombo-occlusive disease of the central chest venus. Chest 120: 1570-1576.

18. Yiltok SJ, Orkar KS, Agaba E, Agbaji O, Legbo JN, Anteyi EA (2005 ) 
Citation: Kane Y, Cisse MM, Gaye M, Seck SM, Lemrabott AT, et al. (2015) Problematic of Vascular Access for Hemodialysis in Sub-Saherienne Africa: Experience of Dakar. J Nephrol Ther 5: 216. doi:10.4172/2161-0959.1000216

Arterioveinous fistula for patients on long term hemodialysis in jos, Nigeria. Niger Postgrad Med J 12: 6-9.

19. Kairaitis LK, Gottlieb T (1999) Outcome and complications of temporary hemodialysis catheter. Nephrol Dial Transplant 14: 1710-1714.

20. Ponikvar R, Buturovic-ponikvar J (2005) Temporary hemodialysis catheters as a long-term vascular access in chronic hemodialysis patients. Ther Apher Dial 9: 250-253.

21. ${ }^{* * *}$ www.sfav.org
22. Jennings WC (2006) Creating Arteriovenous Fistulas in 132 Consecutive Patients. Arch Surg 141: 27-32.

23. Ravani P, Marcelli D, Malberti F (2002) Vascular access surgery managed by renal physicians: The choice of native arterio-venous fistulas for hemodialysis. Am J Kidney Dis 40: 1264-1276.

24. Bensalem S (2009) P49 Spécificités des complications des fistules artérioveineuses chez les diabétiques en hémodialyse. Diabètes and métabolism 35: A40. 